\title{
ARQUEOLOGIA BRASILEIRA. UMA PERSPECTIVA HISTÓRICA E COMPARADA
}

\author{
Cristiana Barreto*
}

\begin{abstract}
"By documenting the past experience of the discipline and shedding light on the processes of archaeological knowledge production, history can articulate with theoretical and methodological problems and play an active role in reorienting both contemporary and future archaeological practice" (Pinsky 1989:90).
\end{abstract}

Este artigo é, antes de tudo, um convite aos arqueólogos brasileiros para refletirmos sobre as inspirações teóricas e rumos tomados pela arqueologia no Brasil, a partir de uma perspectiva histórica e comparativa, e com o intuito de favorecer o desenvolvimento de uma arqueologia verdadeiramente nacional, isto é, moldada aos problemas e condições específicas que a herança arqueológica brasileira apresenta.

Esta preocupação com o desenvolvimento de uma arqueologia orientada para um contexto especificamente brasileiro surge da convicção de que a natureza do registro arqueológico determina, ao menos em parte, o conhecimento produzido sobre ele, uma posição defendida por alguns analistas e historiadores da arqueologia (Salmon 1982; Wyllie 1991, 1993) enquanto alternativa ao recente relativismo radical proposto por alguns críticos pós-processuais (Shanks e Tilley 1990).

Mais especificamente, acreditamos que se interpretações arqueológicas são necessariamente permeadas por (pré)conceitos do presente, elas não são de todo flexíveis e que a própria natureza do registro arqueológico e seu contexto específico tornam suas interpretações diferentes de meras opiniões arbitrárias. Daí a importância de desenvolvermos uma arqueologia que, na es-

(*) Doutoranda da Universidade de Pittsburgh, EUA. colha de suas inspirações teóricas e práticas metodológicas, considere as especificidades do registro arqueológico com que se está lidando. Espera-se com isto desenvolver uma produção mais sólida em termos interpretativos e mais responsável quanto às visões que oferece à sociedade nacional (e demais grupos interessados) do passado pré-colonial brasileiro.

A arqueologia brasileira tem sido caracterizada como pouco teórica e isolada do contexto internacional. Uma análise crítica de seu desenvolvimento histórico e a comparação deste com o da arqueologia de outros países contribui para trazer à tona as teorias arqueológicas usadas no Brasil e situar a Arqueologia brasileira no contexto da Arqueologia internacional contemporânea.

Este artigo apresenta uma pequena amostra de como este trabalho analítico pode ser conduzido, abordando alguns temas que tratam tanto do papel social da Arqueologia (por exemplo, os usos políticos do patrimônio arqueológico), como de uma reavaliação das inspirações teóricas adotadas nas últimas décadas.

\section{História crítica e comparativa da arqueologia:} um instrumento de análise e avaliação

Nas últimas duas décadas, a arqueologia contemporânea passou por um processo bastante decisivo de debates, críticas, e revisões de 
linhas teóricas dominantes, desembocando em um pluralismo teórico, temático, e metodológico jamais visto na história da arqueologia ocidental. Inicialmente desencadeado pelas críticas contundentes vindas de Cambridge à arqueologia processual anglo-saxônica, e depois continuado com o aparecimento de um novo leque de perspectivas teóricas, este processo também veio ressaltar a importância de uma arqueologia mais reflexiva quanto à sua natureza e mais consciente de seu papel social.

Foi dentro deste contexto que filósofos da ciência, historiadores das idéias, e os próprios arqueólogos se debruçaram sobre o passado da arqueologia para, a partir de uma historiografia crítica, entender as configurações, compromissos, e rumos atuais da disciplina. Trabalhos como os de Trigger (1989), Patterson (1986, 1991), Leone (1986) e ainda aqueles editados por Pinsky e Wylie (1989), Hodder (1991) e Ucko (1995), entre outros, demonstram como os arqueólogos, a partir de uma perspectiva interna da disciplina, ao analisar criticamente a sua história, podem fornecer instrumentos fundamentais para expor a estrutura e organização interna da arqueologia, entender os vários processos de seu desenvolvimento e, o mais importante, para se avaliar e reformular dilemas teóricos e metodológicos contemporâneos.

$\mathrm{Na}$ América Latina, o desenvolvimento da arqueologia também tem sido pensado com a ajuda de historiografias críticas como demonstram as coletâneas editadas por Politis (1992) e Oyuela-Caycedo (1994) e debates recentes (Patterson 1994, Oyuela-Caycedo et al. 1997, Lizárraga 1999). Uma preocupação constante nas análises resultantes são as consequiências sociais, políticas, e culturais do trabalho da arqueologia, ressaltando a importância decisiva das inspirações teóricas adotadas para a definição de questões como as relativas a identidade cultural, preservação do patrimônio, ou à projeção da produção científica na educação (Mokus 1992).

No Brasil, apesar de o papel da arqueologia perante a sociedade nacional ser cada vez mais marcante, este papel só agora começa a ser discutido pela comunidade arqueológica. A autoridade do arqueólogo enquanto especialista se afirma cada vez mais: a crescente prática da arqueologia contratual no Brasil confere ao arqueólogo não só o poder de avaliar a relevância e a impor- tância do patrimônio arqueológico para a sociedade nacional como um todo, como também o de tomar decisões irreversíveis sobre qual parte deste patrimônio deve ser preservada. Apesar de este poder estar embasado no reconhecimento (ao menos por parte da lei) do saber científico e da integridade moral desta classe de especialistas, a possibilidade de ele ser permeado por interesses de grupos distintos (como o governo, empreiteiras, ou grupos interessados em afirmar identidades étnicas passadas) estará sempre presente porque o patrimônio arqueológico (em sua materialidade) faz parte de um contexto de valores contemporâneos.

$\mathrm{O}$ fato de a arqueologia ser uma ciência interpretativa, podendo gerar reconstruções alternativas do passado, só vem aumentar a possibilidade destas interferências "externas" ocorrerem. Uma maneira de os arqueólogos se protegerem contra estas possíveis interferências é a de explicitar e fortalecer a relação entre os princípios que guiam o seu trabalho (tradições teóricas e teorias particulares, modelos, hipóteses etc.) e as interpretações do passado que apresenta à sociedade. Apesar deste papel decisivo da teoria enquanto fundação ou suporte para a produção do arqueólogo, no Brasil, as discussões sobre a atuação do arqueólogo na sociedade não visam explicitar as tradições teóricas em uso na arqueologia brasileira, as quais, no entanto, necessariamente permeiam a relação entre o arqueólogo e a sociedade.

Uma perspectiva histórica da arqueologia brasileira permite explicitar não só as correntes teóricas que influenciaram a produção até hoje e entender como se chegou ao cenário atual de usos de teoria tão pouco explícitos, quase nunca discutidos, e geralmente desprezados na arqueologia brasileira.

É verdade que as histórias da arqueologia brasileira existentes já teceram um trabalho importante de avaliação da influência de profissionais ou instituições específicas na produção científica da área, e algumas chegam até mesmo a caracterizar escolas ou correntes dentro da arqueologia brasileira (Barreto 1992; Mendonça de Sousa 1991; Prous 1980, 1992; Prous e Ribeiro 1985; Dias 1995; Schmitz 1994). Estas histórias, no entanto, não permitem uma leitura analítica dos princípios teóricos que inspiraram e organizaram a arqueologia brasileira ao longo dos tempos. 
BARRETO, C. Arqueologia brasileira: uma perspectiva histórica e comparada. Rev. do Museu de Arqueologia e Etnologia, São Paulo, Suplemento 3: 201-212, 1999.

Já em uma outra vertente de análise está o trabalho de Funari $(1989,1992,1994,1995,1996$, 1998) que, apesar de reconhecer a importância da teoria na arquelogia, trabalhando contra a dificuldade que ele mesmo admite em mapear seus contornos em contexto brasileiro, é marcado por uma preocupação bastante doutrinária em identificar agendas políticas e ideológicas no discurso de determinados grupos na história da arqueologia brasileira, sem no entanto explorar a fundo as teorias em torno das quais estes grupos organizaram sua produção científica, e tampouco analisa os efeitos desta produção para a construção de um passado arqueológico nacional.

Ao refletirmos sobre a arqueologia brasileira, a comparação com o desenvolvimento da arqueologia em outros países, sobretudo os da América Latina, além de evidenciar os contextos e processos de organização da produção científica que compartilhamos com outros países, também evidencia os processos dos quais a arqueologia brasileira ficou à margem e os motivos de tal isolamento.

A comparação com outros países da América Latina é necessariamente no sentido de buscar novos caminhos para problemas mais ou menos semelhantes. Apesar da especificidade de como a arqueologia se desenvolveu em cada país, ficam claras as semelhanças e diferenças no desenvolvimento da disciplina de acordo com certos processos históricos compartilhados ou não, como por exemplo, os processos históricos de dizimação das populações indígenas e a inclusão destes em processos de formação de uma identidade nacional, como a herança cultural é aproveitada por movimentos sociais e políticos nacionais, e o grau de colonialismo cultural no desenvolvimento da reconstituição do passado nacional.

Sem dúvida, seria igualmente produtivo se nos voltássemos também para a história da arqueologia em outros países "marginais", como a Austrália, e certos países africanos.

Este recurso analítico, a comparação do desenvolvimento da arqueologia no Brasil com a de outros países, também ainda não foi explorado nas poucas análises reflexivas existentes.

Aqui, esboçamos uma tentativa inicial de desenvolvermos alguns temas sob uma perspectiva histórica comparativa e crítica com o objetivo de contribuir para uma arqueologia mais infor- mada sobre as inspirações teóricas que organizam sua prática, mais consciente de seu papel social e, portanto, mais responsável na sua tarefa de resgatar e reproduzir a cultura nacional.

\section{Arqueologia nacional: uma arqueologia brasileira?}

Todas as histórias da arqueologia brasileira enfatizam o rápido desenvolvimento da disciplina nas últimas décadas, sobretudo o aumento de produção científica e institucionalização de pesquisas a partir de 1950 (por exemplo Prous 1992, Schmitz 1994). Outros autores (Barreto 1998, Funari 1989, Neves 1988) apontam para um desenvolvimento também marcado pelo isolamento e marginalização da arqueologia brasileira em relação à arqueologia do restante da América Latina e do cenário internacional em geral. Enquanto nestas últimas décadas foram publicados em revistas internacionais e especializadas quer o trabalho empírico da arqueologia desenvolvida na maioria de outros países da América Latina (como por exemplo a revista Latin American Antiquity), quer os debates teóricos entre as diversas correntes contemporâneas da arqueologia americana (como por exemplo na Revista de Arqueología Americana) muito pouco da arqueologia brasileira foi representada neste contexto internacional

Com exceção das polêmicas sobre a antigüidade de alguns sítios isolados e debates sobre a possibilidade de sociedades complexas terem se desenvolvido na Amazônia (ambos os temas tratados basicamente só por arqueólogos estrangeiros), a grande parte da produção científica brasileira, a qual já cobre praticamente todo o território nacional e todos os períodos do passado brasileiro, é desconhecida no exterior.

Este isolamento pode ser explicado por vários fatores, a começar pela língua pouco lida em que a maior parte da produção sobre arqueologia brasileira é publicada. A falta de conhecimento e interesse pela comunidade internacional também pode ser explicada pela ausência de um patrimônio monumental arquitetônico que atraísse a atenção de arqueólogos estrangeiros desde o século passado (a exemplo dos países andinos e da Mesoamérica) e pela imagem do Brasil como um território de condições inóspitas para a pesquisa arqueo- 
lógica (coberto por florestas tropicais e pouca preservação de restos arqueológicos), inibindo o desenvolvimento de projetos de pesquisa por parte de instituições e pesquisadores estrangeiros até a década passada. É ainda possível que um certo provincianismo e a formação de "feudos acadêmicos" (como se referem Funari 1998 e Roosevelt 1991) tenham dificultado a entrada de mais projetos estrangeiros e de cooperação internacional que abrissem portas para a produção brasileira no contexto internacional.

Contudo, ao nosso ver, nenhum destes fatores foi tão decisivo quanto o caráter essencialmente descritivo e aparentemente "ateórico" da produção brasileira que não só acabou por afastar a arqueologia brasileira dos debates teóricos internacionais mas também diminuiu o interesse da comunidade científica internacional pelos casos empíricos brasileiros.

Mantendo-se isolada, a arqueologia brasileira, não só absorveu muito pouco dos debates e avanços teóricos do cenário internacional das últimas décadas, como também não chegou a se constituir em uma arqueologia nacional, particularmente concebida para os problemas do passado brasileiro e, menos ainda, em uma arqueologia nacionalista, voltada para a afirmação de ideais nacionais.

Acreditamos que esta situação foi moldada por dois fatores ao longo da história da arqueologia no Brasil: as circunstâncias históricas que afastaram a arqueologia da antropologia cultural, e das ciências sociais em geral; e o uso pouco consciente, inadequado, ou ainda mal adaptado ao contexto brasileiro, de teorias e práticas metodológicas introduzidas no Brasil por escolas estrangeiras (Barreto 1998).

\section{Arqueologia e identidade nacional}

"Na nossa cultura há uma ambigüidade fundamental: a de sermos um povo latino, de herança cultural européia, mas etnicamente. mestiço, situado no trópico, influenciado por culturas primitivas, ameríndias e africanas." (Antonio Cândido 1985:119).

A história da arqueologia brasileira é a história do confronto do brasileiro com seu passado cultural. Por isso reflete a ambigüidade a que se refere Antonio Cândido na nossa cultura. A ar- queologia brasileira fica entre uma arqueologia do "outro" (o outro, no caso, sendo sobretudo o indígena), e uma arqueologia "de nós mesmos" na qual há uma real identificação cultural com as sociedades passadas estudadas.

A perspectiva da arqueologia do outro foi herdada principalmente da arquelogia colonial européia do século XVIII, cujos modelos foram seguidos tanto por europeus como brasileiros que inauguraram a prática da pesquisa arqueológica no Brasil. Assim, desde as primeiras explorações do território brasileiro, os objetos arqueológicos só são tratados como objeto de estudo por sua exoticidade, suas diferenças em relação aos padrões culturais europeus, e sobretudo por se prestarem a exercícios interpretativos condizentes com a mentalidade colonial, a exemplo do Gabinete Real de Curiosidades (Lopes 1997).

Mesmo com a vinda da corte ao Brasil no início do século XIX, com a qual se valoriza o conhecimento mais sistemático da natureza e das populações indígenas, a perspectiva continua sendo essencialmente colonial. $O$ estudo das antigas culturas indígenas é incentivado e praticado pelas elites do saber no sentido de fortalecer a imagem de um país vasto, diversificado, e cheio de riquezas naturais, mas nunca de forma a fortalecer o incipiente nativismo brasileiro.

Com isto, a arqueologia nasce no Brasil esvaziada de sentido político quanto à identificação da sociedade com o passado estudado, contrastando fortemente com uma outra tradição Latino-americana, tanto em países andinos quanto no México, na qual a preservação e o estudo do patrimônio arqueológico tornou-se, ao longo da história, instrumento quer de resistência política ao colonialismo europeu, quer de afirmação de ideologias nacionalistas, anti-coloniais e revolucionárias.

No Brasil, ao contrário destes países, a arqueologia é uma prática confinada aos museus até praticamente a década de 1950 . Protegida de qualquer uso social ou político, a arqueologia é concebida como mais próxima das práticas classificatórias das ciências naturais, da história natural, implantada no país sobretudo por naturalistas alemães no fim do século passado e início deste. $\mathrm{O}$ exemplo da produção de von Ihering junto ao Museu Paulista e seu tratamento das coleções arqueológicas (Lopes 1997) seja talvez o mais representativo desta forte herança do "na- 
BARRETO, C. Arqueologia brasileira: uma perspectiva histórica e comparada. Rev. do Museu de Arqueologia e Etnologia, São Paulo, Suplemento 3: 201-212, 1999.

turalismo" alemão presente ainda hoje na arqueologia brasileira.

Também até então, as poucas tentativas de se transcender um mero taxonomismo arqueológico tratavam de identificar diferentes raças ou diferentes origens da população pré-histórica brasileira (representadas nas típicas expressões da época como a "Raça de Lagoa Santa" ou o "Homem dos Sambaquis"). A inspiração maior vem claramente da arqueologia européia do começo deste século, uma arqueologia particularmente marcada por preocupações nacionalistas e a decorrente necessidade de se investigar origens e diferenciações étnicas dos vários povos europeus.

Paradoxalmente, apesar de o Brasil ter passado por movimentos artístico-literários de revalorização das origens e do passado indígena brasileiro (como no romantismo e no modernismo), a arquelogia nunca compartilhou destas inspirações nacionalistas. Herdou-se, no entanto, uma orientação predominantemente historicista e difusionista européia, mas sem suas inspirações ideológicas e teóricas originais.

Mesmo em momentos políticos que exigiam a reconstrução da história nacional, a arqueologia é chamada para revelar o passado pré-colonial dos brasileiros segundo um modelo de história predominantemente europeu. Por exemplo, quando da proclamação da República, a arqueologia é sim absorvida por movimentos ufanistas que, ao invés de valorizar o indígena brasileiro $e$ o patrimônio já conhecido, incentivaram a busca de "cidades perdidas" ou outras provas da existência de "altas" culturas a exemplo das culturas conhecidas na Europa e suas colônias (Mendonça de Souza 1991 faz uma boa descrição destes movimentos).

Nas décadas de 1920 e 1930, o movimento modernista, numa revalorização do passado nacional, não só mais consciente da ambigüidade que permeia nossa cultura, mas também mais agressiva quanto ao resgate de nossas raízes pré-coloniais, rompe com o modelo de cultura nacional europeizado. Como descreve Antonio Cândido, "nossas deficiências, supostas ou reais, são reinterpretadas como superioridades"(1985:120), e nosso patrimônio arqueológico passa a ser revalorizado dentro de um novo contexto mais amplo de patrimônio cultural nacional.
A preocupação com a preservação deste patrimônio se traduz no projeto de lei elaborado por Mario de Andrade em 1936 que, desfigurado de seus conceitos originais, acaba vingando, através da legislação promulgada pelo Estado Novo, de forma ineficiente e pouco adequada à realidade do patrimônio brasileiro (Andrade Lima 1988). Em um país onde a maior parte do patrimônio arqueológico pré-colonial está materializado em restos de artefatos de pedra ou cerâmica, a legislação que privilegia o patrimônio de pedra e cal - palácios, igrejas, fortalezas - acaba não só por diminuir a importância do patrimônio deixado por sociedades indígenas, mas também enfraquece o próprio papel da arqueologia como responsável pelo seu resgate (Andrade Lima 1988, Falcão 1984). Mais uma vez o modelo europeu não serviu à realidade do patrimônio arqueológico brasileiro.

Tal fenômeno não ocorre em países da América Latina nos quais a arqueologia, também impulsionada por movimentos de revalorização do passado pré-colonial, como o "Indigenismo" mexicano e peruano dos anos 1920s e 1940s respectivamente, conta com um patrimônio material de pirâmides, templos e palácios que melhor se acomodavam dentro dos parâmetros europeus de preservação de patrimônio arqueológico. Por outro lado, tais movimentos de valorização do passado indígena tem uma real ação transformadora na prática da arqueologia nestes países, seja do ponto de vista dos métodos de preservação e reconstrução do patrimônio arqueológico, seja do ponto de vista de pesquisa e geração de teorias interpretativas.

No México, o nacionalismo revolucionário engendrou toda uma tradição de reconstrução de ruínas arqueológicas, onde se privilegia uma aparência atraente às classes populares de forma a reforçar o sentimento de identidade nacional e a glorificação de um passado pré-hispânico. O trabalho de Manuel Gamio que tranformou Teotihuacan em símbolo de integração nacional talvez seja o exemplo mais ilustrativo de como perspectivas nacionalistas engendram uma nova prática arqueológica (Lorenzo 1982, McGuire 1992: 63).

No Peru, onde o indigenismo de Mariategui (1943) associa as sociedades indígenas ao socialismo, e o Estado Inca a um Estado socialista primitivo, arqueólogos como Julio C. Tello propõem teorias sobre o desenvolvimento local de 
sociedades complexas, distanciando-se do difusionismo de arqueólogos estrangeiros como o de Max Uhle (Patterson 1989).

No Brasil, a primeira vez que a arqueologia assume de fato um significado político é também através da questão de proteção do patrimônio arqueológico nacional. Campanhas preservacionistas, como as lideradas, na década de 1950 por Paulo Duarte em São Paulo, José Loureiro Fernandes no Paraná, e Luis de Castro Faria no Rio de Janeiro, tiveram consequiências inovadoras no sentido de favorecer a institucionalização acadêmica da Arqueologia e com isso a formação de uma geração de arqueólogos brasileiros e o início de pesquisa científica dentro da universidade.

Já em 1935, Luis de Castro Faria, uma das personalidades mais atuantes na defesa do patrimônio arqueológico, funda o Centro de Estudos Archeológicos, mais tarde absorvido pelo Museu Nacional e que, pela primeira vez no Brasil, conferia nível acadêmico à arqueologia, servindo de modelo a outras instituições de pesquisa arqueológica no Brasil.

Em São Paulo, foi também assim que a "Comissão de Préhistória", criada por decreto em 1952 e fruto da conhecida luta política de Paulo Duarte para a preservação dos sambaquis, tornase o núcleo do futuro Instituto de Préhistória junto à USP.

Este mesmo processo ocorre no Paraná onde a ação preservacionista dá origem a centro acadêmico com a ação de José Loureiro Fernandes, importante personalidade das campanhas de proteção dos sambaquis, desembocando na criação do Centro de Ensino e Pesquisas Arqueológicas (CEPA) junto a Universidade Federal do Paraná em 1956.

Portanto, também no Brasil, o preservacionismo acaba por gerar conseqüências bastante positivas. Nossos primeiros e mais marcantes centros acadêmicos são fruto de uma política preservacionista antes de mais nada preocupada em garantir os direitos à pesquisa científica de um patrimônio em crescente destruição.

No entanto, diferentemente das duas experiências latino-americanas citadas acima, as mudanças geradas a partir dos movimentos de preservação não estavam ligadas a interesses políticos ou ideológicos; nem a interesses nacionalistas (como no caso do México) nem a ideais de reafirmação de uma arqueologia nacional (como no caso do Peru). Os centros acadêmicos criados nesta época eram frutos de esforços concertados de determinados indivíduos, todos de certa forma representantes de uma elite intelectual empenhada no desenvolvimento da disciplina no Brasil como sempre seguindo à risca os moldes europeus. Assim as consequiências do preservacionismo no Brasil, ao invés de reforçar uma arqueologia nacional, vem apenas ampliar a ambigüidade de sua identidade cultural acadêmica.

Nas décadas de 1960 e 1970, enquanto o marxismo e Arqueologia Social se desenvolvem em alguns países da América latina, no Brasil, a arqueologia, por razões analisadas a seguir, estava já bastante isolada das ciências sociais. Enquanto nas ciências sociais grupos representativos da intelectualidade brasileira se posicionavam abertamente contra o regime militar, os arqueólogos, via de regra, parecem ter ficado à margem dos eventos tanto de engajamento político aberto, como da censura e repressão política que recaíram sobre as universidades brasileiras neste período. Neste sentido, é falsa qualquer tentativa de caracterizar uma politização da disciplina para este período como o faz Funari (1992). Ao contrário, pode se dizer que a arqueologia foi até mesmo um pouco rejeitada pelas ciências sociais, justamente por não contar com um quadro teórico compatível com as teorias e ideologias da esquerda da época e por não participar no engajamento político tão típico dos intelectuais brasileiros de então (Barreto 1997).

Por outro lado, também não há registro de qualquer uso político do patrimônio arqueológico nacional por parte do regime militar, o qual não deixou de explorar determinados símbolos da cultura nacional para sua propaganda política.

Ao longo das últimas décadas, mesmo que determinadas linhas de pesquisa dentro da Arqueologia brasileira, como a Etnoarqueologia ou a Arqueologia Histórica, venham priorizar a reconstrução de passados mais recentes, muitas vezes de sociedades ainda em vida, a produção arqueológica não chega a veicular fora da comunidade acadêmica, e quando o faz (através de museus e poucos livros escolares) é desprovida de qualquer sentido político.

Enfim, concluímos que numa breve análise da história da arqueologia brasileira no que diz respeito à contribuição da arqueologia para a reconstrução de um passado e identidade nacionais, 
BARRETO, C. Arqueologia brasileira: uma perspectiva histórica e comparada. Rev. do Museu de Arqueologia e Etnologia, São Paulo, Suplemento 3: 201-212, 1999.

fica notória a ausência de uma tradição de usos políticos do patrimônio arqueológico.

Mesmo nos dias de hoje, em que as sociedades indígenas cada vez mais conscientes de seu passado de dizimação, perda de territórios, e realocação forçada, não têm feito uso do patrimônio arqueológico para suas lutas políticas, ou mesmo para reafirmação de suas identidades indígenas. Os casos em que isto acontece são ainda raros e questões como a repatriação ou o reenterramento de materiais arqueológicos, a exemplo das exigências de grupos indígenas norte-americanos, estão ainda por ser introduzidos no Brasil.

Esta situação é bastante contrastante com a de outros países latino-americanos, sobretudo daqueles onde ainda sobrevivem grandes contigentes populacionais de descendência indígena. Talvez o exemplo mais radical de sucessivos usos políticos do patrimônio arqueológico que temos na América Latina seja o do México, que começa com os próprios Astecas (e possivelmente até antes), passando pela destruição e censuras deste patrimônio pelos espanhóis em tempos coloniais, sendo depois recuperado pela Revolução Mexicana em sua tarefa política de prover os mexicanos com um passado próprio, uma história nacional, a qual finalmente se transforma em história oficial hoje questionada por minorias étnicas como os Maia de Chiapas.

Neste sentido, a história da arqueologia brasileira se aproxima mais da dos países latinoamericanos em que não só as populações indígenas são pouco expressivas numericamente como também apresentam um patrimônio arqueológico que, por seu caráter pouco monumental, é mais dificilmente recuperável enquanto símbolo de cultura nacional.

\section{A arqueologia acadêmica brasileira: inspirações teóricas}

Diferentemente das outras ciências sociais no Brasil, a arqueologia surge dentro das universidades, não através de projetos intelectuais específicos, mas a partir de campanhas preservacionistas externas ao mundo acadêmico, promovidas por alguns poucos intelectuais. Portanto a arqueologia surge praticamente à margem dos projetos intelectuais mais amplos do ensino das ciências sociais no Brasil. Ela é incorporada à uni- versidade como uma disciplina à parte, sem projeto curricular específico, sem modelo teórico algum, além de um corpo docente totalmente desprovido de especialistas.

No entanto, com os centros de pesquisa inseridos em universidades, a arqueologia não deixa de desfrutar do principal recurso utilizado na implantação de centros universitários no país, os especialistas estrangeiros. Vista a falta de projeto acadêmico específico para a arqueologia, são estes especialistas estrangeiros que, na verdade, cunharão as principais inspirações teóricas da arqueologia brasileira e terão papel decisivo na formação das futuras gerações de arqueólogos.

Justamente por causa desta importância decisiva, o legado de arqueólogos estrangeiros para o desenvolvimento da disciplina no Brasil não pode ser tratado apenas destacando-se suas contribuições individuais, como fazem a maioria dos historiadores da arqueologia brasileira. Este legado deve ser entendido dentro do contexto histórico específico da arqueologia local, trazendo à tona as condições existentes para a recepção de novas idéias pela comunidade acadêmica local, conjuntamente com a uma análise da bagagem cultural que influenciaram as ações dos especialistas estrangeiros em terreno brasileiro.

Como do lado brasileiro os centros acadêmicos não surgem dentro de um projeto ou tradição teórica específicos, mas sim de uma preocupação em resgatar e preservar, sem necessariamente interpretar, o convite a especialistas estrangeiros e o entusiasmo em absorver um novo saber residia essencialmente nas áreas mais técnicas da arqueologia, sobretudo métodos de escavação, classificação, datação, e documentação. Estes porém não poderiam ser aplicados ao contexto brasileiro de forma teoricamente neutra e estavam necessariamente imbuídos das tradições teóricas de suas matrizes de origem.

As conseqüências destas tradições teóricas se refletem no legado das escolas estrangeiras na arqueologia brasileira contemporânea de diversas maneiras, iniciando-se pelo próprio conceito de arqueologia como disciplina acadêmica. Com a presença bastante expressiva de intelectuais europeus, e sobretudo franceses, a arqueologia é inserida na universidade, seguindo o modelo francês, como o estudo do passado pré-histórico humano, isto é como pré-história, herdando assim toda a ambigüidade e problemas envol- 
BARRETO, C. Arqueologia brasileira: uma perspectiva histórica e comparada. Rev. do Museu de Arqueologia e Etnologia, São Paulo, Suplemento 3: 201-212, 1999.

vidos em se delimitar este período da história humana que, na Europa, tradicionalmente se definiu como aquele que antecede a escrita. Apresentam-se ainda os problemas adicionais da transposição de tal conceito para terreno brasileiro, que, de certa forma, tem sido elegantemente corrigido por arqueólogos contemporâneos brasileiros com o uso da expressão "pré-colonial" ao invés de "pré-histórico"

É a forte tradição européia que fez com que no Brasil a arqueologia inicialmente tenha ficado mais próxima da História Natural, passando depois a ser parte da História, e se desenvolvido como uma sub-disciplina da História (como Préhistória), jamais como uma ciência social ou, mais especificamente como Antropologia. Esta é uma situação bastante paradoxal, uma vez que a maior parte da arqueologia feita no país se dedica ao estudo do passado das sociedades indígenas.

Assim, enquanto o campo da Antropologia e o estudo das sociedades indígenas vivas floresce no Brasil a partir dos anos 40 com a vinda de pessoas como Lévi-Strauss ou alunos diretamente treinados por Radcliff-Brown, a arqueologia no Brasil desenvolve-se sem incorporar as teorias estruturalistas ou funcional-estruturalistas que predominaram e ainda predominam na antropologia no Brasil.

Por outro lado, apesar de próxima à História, a arqueologia no Brasil também não absorveu nada da forte influência dos historiadores marxistas ingleses (tão influentes na história colonial /econômica do Brasil) e tampouco da influência francesa dos historiadores da École des Annales, também bastante forte nos departamentos de História no Brasil, e hoje recuperados por algumas correntes pós-processuais na arqueologia internacional.

$\mathrm{O}$ distanciamento da arqueologia brasileira da tradição marxista das ciências sociais no Brasil e na América Latina em geral, também a manteve isolada da "Arqueologia Social" desenvolvida e compartilhadas por comunidades arqueológicas em países como a Venezuela, a Colômbia, o Peru e o México.

Os historiadores da arqueologia na América Latina, e sobretudo da Arqueologia Social, observam que apesar de todos os problemas intrínsecos desta corrente arqueológica, sobretudo na construção de uma ponte entre teoria e método, ela proporcionou a integração da arqueologia latino-americana em dois níveis. Primeiro, atravessando as barreiras das arqueologias ofi- ciais nacionais, proporcionando teorias e linguagens comuns e, mais recentemente, oferecendo uma visão crítica das arqueologias trazidas de fora, tanto da arqueologia processual como novas linhas pós-processuais. Segundo, a Arqueologia Social, integra arqueologia e história, pois ela apresenta um quadro teórico que pode ser usado para a história dos povos em geral, e não necessariamente cortada em pré-história e história (Patterson 1992, 1994).

Estas diferenças na formação intelectual das comunidades arqueológicas brasileiras e destes outros países da América latina, podem então nos ajudar a entender porquê a arqueologia brasileira ficou tão isolada tanto como uma disciplina em relação às demais ciências sociais, como também isolada de contextos internacionais.

No Brasil, a arqueologia parece ter ficado soterrada sob a carapaça de uma linguagem técnica, desumanizada: fala-se em artefatos, camadas estratigráficas, e sítios arqueológicos, ao invés de culturas, períodos históricos, e assentamentos humanos. Sob este tecnicismo, talvez necessário para a sua aceitação enquanto saber especializado, a arqueologia torna-se pouco atraente aos historiadores e antropólogos que acabam por preferir a utilização de outros recursos para traçarem a história de povos indígenas brasileiros, como os documentos coloniais ou a história oral (Carneiro da Cunha 1992).

Um exemplo desta concepção e aplicação do estudo das sociedades indígenas extintas brasileiras são as definições de pré-história de Paulo Duarte, nas quais afasta a disciplina da História, priorizando as ciências naturais, e também a distingue da Etnologia:

“.... a Arqueologia Clássica acha-se intimamente ligada à Arte e à História, ao passo que a Etnologia e a Préhistória têm ligações estreitas com numerosas disciplinas da História Natural, como a Paleontologia, a Geologia, de que depende a estratigrafia (sem a qual não pode haver escavações pré-históricas), a Química, a Física, a Zoologia, a Botânica, a Anatomia, a Fisiologia, e outros ramos científicos ..."(Paulo Duarte 1977, apud Funari 1994: 164) ......

“...o termo Etnologia não abrange a Préhistória pois, como ensina um notável professor da Sorbonne, que é Lionel Ballout, "o método fundamental da Etnologia é o inquérito entre vivos, inaplicável à humanidade extin- 
ta, que pertence à Préhistória..."(Paulo Duarte 1974, apud Funari 1996: 262).

É portanto dentro deste isolamento das ciências humanas em geral, desta ambigüidade conceitual sobre a natureza da arqueologia, e deste "tecnicismo" promovido pela emergente arqueologia acadêmica, que passam a atuar os arqueólogos estrangeiros na pesquisa e formação de novos arqueólogos no Brasil.

\section{A arqueologia francesa e suas missões no Brasil}

O papel das "missions archéologiques" no Brasil deve ser entendido dentro do projeto maior de missões arqueológicas francesas na América Latina (Prous 1995, Legoupil 1998). Estas missões nascem do interesse crescente desde o início deste século em se pesquisar culturas préhistóricas da América Latina menos conhecidas do que as famosas culturas Maia, Asteca, ou Inca. $\mathrm{Na}$ verdade, desde a criação da Sociedade dos Americanistas em 1876, que o "americanismo" passa a ser uma nova via de estudos (assim como o "africanismo") para historiadores e etnólogos franceses, possibilitando inclusive a formulação de novos paradigmas de pensamento (Massi 1989). Atualmente existem dezessete Missões arqueológicas distribuídas na América Latina (Legoupil 1998).

É dentro do modelo de pesquisas etnológicas praticadas pelo Musée de l'Homme de Paris, e das pioneiras expedições de seu diretor, o americanista Paul Rivet, que chegam ao Brasil as influências francesas na área da arqueologia. Paul Rivet, a convite de seu amigo pessoal Paulo Duarte, integra o grupo já considerável de historiadores, sociólogos e etnólogos franceses que viriam fundar e desenvolver as ciências sociais na Universidade de São Paulo. Vale a pena ressaltar que o incentivo de Paul Rivet não se limita ao apoio intelectual mas também institucional, incluindo recursos financeiros colocados à disposição da Universidade de São Paulo para a criação de "um laboratório de pesquisas sobre as origens e a vida do Homem paleoamericano" (Duarte 1977, apud Funari 1994), o que futuramente se transformaria em Instituto de Préhistória.

A maior influência deu-se porém por meio da atuação do casal Joseph Emperaire e Annette
Laming, trazido por Rivet, e cujas contribuições são bastante reconhecidas em termos tanto de formação científica de uma nova geração de arqueólogos brasileiros, como de introdução de métodos científicos mais rigorosos ao estudo de certos tipos de sítios brasileiros, como os sambaquis (Barreto 1998, Mendonça de Souza 1991, Prous 1995).

$\mathrm{Na}$ bagagem metodólogica trazida para o Brasil pelo casal estavam fatalmente os ensinamentos de mestres como Leroi-Gourhan aplicados ao contexto de sítios paleolíticos franceses. Assim, no Brasil, trabalharam principalmente sítios précerâmicos, concentrando-se em métodos de escavação de superfícies amplas para a reconstrução de solos de ocupação de determinados sítios, e na análise de artefatos, essencialmente líticos, dentro das tipologias e terminologias francesas da época. Seus seminários e manuais sobre análise de artefatos líticos marcaram toda uma geração de arqueólogos até hoje atuantes na arqueologia brasileira (Emperaire 1967).

A priorização do estudo de determinados sítios de um passado distante que nada têm a ver com as sociedades indígenas atuais, juntamente com a introdução de todo um novo jargão técnico, tornaram os resultados de suas pesquisas pouco atraentes ao resto da comunidade acadêmica e ao público em geral que não mais acompanhava a relevância de tais estudos.

Ao contrário da França, no Brasil, onde tão pouco se conhecia da distribuição temporal e espacial das diferentes culturas indígenas extintas, o estudo tão pormenorizado de alguns poucos sítios arqueológicos, mesmo que tomados como exemplos típicos de uma unidade maior desconhecida, diante de tão vasto e inexplorado território, tornou-se uma estratégia pouco produtiva. Além disso, as reconstruções de solos de ocupação não levaram em consideração as diferenças dos processos de formação de depósitos arqueológicos em território tropical, onde a atividade biológica é particularmente intensa.

Um outro problema herdado da perspectiva metodológica francesa, foi a importação das categorias classificatórias para indústrias líticas, enquanto arqueólogos se esforçavam para fazer com que uma maioria de instrumentos líticos informais (ou "expedientes" no atual jargão analítico) se encaixasse em categorias inspiradas pela indústria bastante formal de Paleolítico francês. 
Pouca atenção foi dada a aspectos tecnológicos ou funcionais deste tipo de artefatos que poderiam se mostrar mais informativos sobre as culturas que os produziram.

Ao longo das últimas décadas, estes problemas foram certamente trabalhados e adaptados aos contextos locais por toda uma geração de arqueólogos influenciados pela tradição francesa a qual perdura até hoje através das missões arqueológicas em andamento em Minas Gerais, Piauí, e Mato Grosso.

Contudo, esta trajetória de aprendizado de conformação de determinadas metodologias a temas e contextos específicos brasileiros não parece ter sido sistematizada de forma a se constituir em uma verdadeira linha ou escola de pesquisa francesa com variante brasileira. Assim como as próprias missões francesas atuantes no território brasileiro, com exceção de algumas tentativas de padronização terminológica, não há esforços combinados de concordância da comunidade arqueológica nacional em torno de determinadas teorias ou mesmo de práticas metodológicas.

\section{A arqueologia norte-americana e sua atuação no Brasil}

A influência da escola americana na arqueologia é bastante tardia quando comparada a de outros países latino-americanos. Sem dúvida, a falta de monumentalidade e de altas civilizações não atraíram as expedições dos grandes museus americanos do começo do século concentradas então nos Andes e Mesoamérica. Apesar de alguns poucos pesquisadores terem se aventurado a pesquisar as "terras baixas tropicais" poucos têm uma real influência na arqueologia acadêmica brasileira.

Os americanos mais influentes no Brasil, Betty Meggers e Clifford Evans, apesar de terem iniciado suas pesquisas na Amazônia na década de 1940, só terão uma atuação na formação de arqueólogos brasileiros, a partir da década de 1960 . Eles trabalham inicialmente em outros países da América Latina, como o Equador e a Venezuela, deixando nestes países uma herança teórica bastante distinta de suas marcas no Brasil.

Apesar de suas pesquisas na Amazônia terem trazido um pouco do neo-evolucionismo americano e da ecologia cultural da década de 1950 de descendência direta de Julian Steward, fora da
Amazônia, onde houve a formação de arqueólogos brasileiros por meio de seminários e do envolvimento destes em um grande projeto de nível nacional como foi o PRONAPA, esta orientação neo-evolucionista teve pouco impacto na organização da arqueologia brasileira.

Também apesar de a grande contribuição de Meggers dentro da arqueologia se concentrar em seus argumentos apoiados em teorias de determinismo tecno-ambiental, moldando inclusive sua interpretação da ocupação humana da Amazônia, muito pouco deste corpo teórico é de fato passado aos muitos arqueólogos brasileiros por ela orientados.

Categorias evolutivas como arcaico, formativo, e clássico, ou outros tipos de "horizontes" evolutivos, nunca vingaram na arqueologia brasileira moderna. Ao invés, o PRONAPA escolheu organizar seus dados nas categorias também americanas de "fases" e "tradições" (originalmente propostas por Willey e Phillips 1955). Contudo, a forma como estas categorias foram usadas em terreno brasileiro, identificando variantes culturais ou étnicas a uma determinada distribuição de artefatos no tempo ou espaço, se assemelha mais às práticas do difusionismo cultural europeu, do que ao neo-evolucionismo ecológico americano.

Uma das consequiências desta falta de orientação teórica explícita do PRONAPA é a dificuldade de se integrar os dados coletados ao longo de décadas em uma síntese de arqueologia nacional.

Em contraste, em outros países da América do Sul nos quais atuaram Meggers e Evans, a interface de sua bagagem neo-evolucionista com um quadro interpetativo Marxista permitiu não só sínteses de dados arqueológicos em categorias tais como "formações sociais" ou "modos de produção" mas também promoveu a integração da arqueologia nas demais ciências sociais, como uma ciência histórica.

Enquanto a visão de Meggers da Amazônia como o paraíso em que perduraram através de milênios pequenas sociedades igualitárias representa uma questão ideológica em certos países da America Latina, uma visão por vezes defendida por retratar de certa forma a possibilidade de ideais socialistas, no Brasil, ao contrário, esta visão é absorvida despolitizadamente, aceita ou questionada apenas por seu embasamento empírico. 
BARRETO, C. Arqueologia brasileira: uma perspectiva histórica e comparada. Rev. do Museu de Arqueologia e Etnologia, São Paulo, Suplemento 3: 201-212, 1999.

Também enquanto os arqueólogos brasileiros se dedicaram a um único e vasto projeto de levantamento de dados empíricos e se esforçaram em padronizar uma metodologia relativamente simples com o PRONAPA (Dias 1995), outros países das terras baixas da América do Sul, quer por terem mantido contato com outros grupos de arqueólogos americanos, ou quer por terem desenvolvido projetos mais orientados por questões teóricas, acabaram com uma arqueologia mais diversificada e modernizada na coleta de dados empíricos (Stahl 1995).

\section{Considerações finais}

Estes dois exemplos de influências tão marcantes na arqueologia brasileira demonstram como as especificidades das bagagens teóricas trazidas por certas personalidades nem sempre podem por si só explicar os resultados provocados no Brasil. Elas devem ser entendidas dentro dos contextos históricos também bastante específicos de desenvolvimento da comunidade acadêmica de arqueólogos brasileiros.

Para se avaliar as orientações teórico-metodológicas da arqueologia contemporânea no Brasil resta-nos ainda rever de forma sistemática a trajetória de escolha, aprendizado, e adaptação de teorias e práticas arqueológicas provenientes de contextos diversos ao caso nacional por parte da comunidade arqueológica brasileira. Só assim, será possível realmente avaliarmos os caminhos mais adequados ao estudo de nossa herança arqueológica e os resultados mais relevantes para a sociedade nacional como um todo.

Esta trajetória de escolha, aprendizado, e adaptação de diversas teorias e métodos ao contexto brasileiro, por mais que ocorra de forma isolada e desordenada entre os diversos pesquisadores e projetos, possui, no entanto, um denominador comum: o tipo de registro arqueológico e as condições de pesquisa que se apresentam no Brasil. A criação de uma arqueologia nacional deve necessariamente partir deste denominador comum.

\section{Referências bibliográficas}

\section{ANDRADE E LIMA, T.}

1988 Patrimônio Arqueológico, Ideologia e Poder. Revista de Arqueologia, 5 (1): 19-28.

\section{BARRETO, C}

1998 Brazilian archaeology from a Brazilian perspective. Antiquity, 72: 573-81.

BARRETO, M.V.

1992 História da Pesquisa Arqueológica no Museu Paraense Emílio Goeldi. Boletim do Museu Paraense Emilio Goeldi, ser. Antropologia, 8: 203-293.

CÂNDIDO, A.

1985 Literatura e Sociedade. 7a.Edição, São Paulo: Cia. Editora Nacional.

CARNEIRO DA CUNHA, M. (Ed.)

1992 História dos Índios do Brasil. São Paulo: Cia. da Letras.

DIAS, A.S.

1995 Um projeto para a arqueologia brasileira. Breve histórico da implantação do PRONAPA. Revista do CEPA, 22: 25-39.

FALCÃO, J.A.

1984 Política cultural e democracia: a preservação do patrimônio histórico e artístico nacional. S. Miceli (Org.) Estado e Cultura no Brasil. São Paulo: DIFEL.

FUNARI, P.P.A.

1989 Brazilian Archaeology and World Archaeology: some Remarks. World Archaeology Bulletin, 3: 60-68.
1992 La Arqueología en Brasil: Política y Academia en una Encrucijada. G. Politis (Ed.) Arqueologia en America Latina Hoy. Bogotá, Biblioteca Banco Popular: 57-69.

1994 Paulo Duarte e o Instituto de Pré-História: documentos inéditos. Idéias, Campinas, $l$ (1): 155-179.

1995 Mixed Features of Archaeological Theory in Brazil. P.J. Ucko (Ed.) Theory in Archaeology. A World Perspective. London \& New York, Routledge: 236-250.

1996 Um documento inédito de Paulo Duarte. Sae culum, Revista de História da UFPA, 2: 253 264.

1998 A importância da teoria Arqueológica internacional para a arqueologia sul-americana: o caso brasileiro. Texto apresentado na Primeira Reunião de Teoria Arqueológica na América do Sul, Vitória, 6-9 de maio de 1998.

HODDER, I. (Ed.)

1991 Archaeological Theory in Europe: the last three decades. Londres: Routledge.

LEGOUPIL, D.

1998 French Archaeology in Patagonia and Tierra del Fuego. Bulletin of the Society of American Archaeology, 16 (4): 33-36.

LEONE, M.

1986 Symbolic, Structural, and Critical Archaeology. D. Meltzer; D. Fowler; J. Sabbloff (Eds.) American Archaeology: Past and Future. 
BARRETO, C. Arqueologia brasileira: uma perspectiva histórica e comparada. Rev. do Museu de Arqueologia e Etnologia, São Paulo, Suplemento 3: 201-212, 1999.

Washington D.C., Smithsonian Institution Press: 415-438.

LIZÁRRAGA, K.G.

1999 From Social Archaeology to National Archaeology: up from domination. American Antiquity, 64 (2): 363-368.

LOPES, M.M.

1997 Os Museus e as Ciências Naturais no Século XIX. São Paulo: Hucitec.

MENDONÇA de SOUSA, A.

1991 História da Arqueologia no Brasil. Pesquisas, Série Antropologia 46.

MOKUS, A.

1992 Presentación. G. Politis (Ed.) Arqueologia en América Latina Hoy. Bogotá, Biblioteca Banco Popular: 8-12.

NEVES, W.A

1988 Arqueologia brasileira: algumas considerações. Boletim do Museu Paraense Emílio Goeldi, Ser. Antropologia, 2: 200-205.

OYUELA-CAYCEDO, A. (Ed.)

1994 History of Latin American Archaeology. Aldershot: Avebury.

OYUELA-CAYCEDO, A.; ANAYA, A.; ELERA, C.G.; VALDEZ, L.M.

1997 Social Archaeology in Latin America?: Comments to T.C. Patterson. American Antiquity, 62: $365-374$

PATTERSON, T.

1986 The last sixty years: towards a social history of Americanist archaeology in the United Sates. American Anthropologist, 88: 7-26.

1994 Social archaeology in Latin America: an appreciation. American Antiquity, 59: 531-537.

PINSKY, V.

1989 Comments: a critical role for the history of archaeology. V. Pinsky; A. Wylie (Eds.) Critical Traditions in Contemporary Archaeology. Albuquerque, University of New Mexico Press: 89-91.

POLITIS, G. (Ed.)

1992 Arqueología en América Latina Hoy. Bogotá: Biblioteca Banco Popular.

POLITIS, G.

1995 The socio-politics of the development of archaeology in Hispanic South America. J. Ucko (Ed.) Theory in Archaeology. A World Perspective. London, Routledge: 197-235.

PROUS, A.

1980 História da pesquisa e da bibliografia arqueologica no Brasil. Arquivos do Museu de História Natural, 4-5: 11-24.
1992 Arqueologia Brasileira. Brasília: Editora da Universidade de Brasília.

1995 Histórico do Setor de Arqueologia UFMG e Papel das Missões Franco-Brasileiras. Coleção Arqueologia, Porto Alegre, EDIPUCRS, 1 (1): 131-150.

PROUS, A.; RIBEIRO, $\mathrm{H}$.

1985 História da pesquisa e Bibliografia Arqueol6gica no Brasil, Bibliografia Geral II, Arquivos do Museu de História Natural, 10: 46-169.

ROOSEVELT, A.C.

1991 Moundbuilders of the Amazon. Geophysical Archaeology on Marajo Island, Brazil. New York: Academic Press.

SALMON, M.

1982 Philosophy and Archaeology. New York: Academic Press.

SCHMITZ, P.I.

1994 Brazil: tendencies and growth. A. OyuelaCaycedo (Ed.) History of Latin American Archaeology. Avebury, Aldershot: 22-35.

SHANKS, M.; TILLEY, C.

1989 Archaeology into the 90's. Norwegian Archaeological Review, 21: 1-54.

STAHL, P.W. (Ed.)

1995 Archaeology in the Lowland American Tropics: Current Analytical Methods and Recent Applications. Cambridge: Cambridge University Press.

TRIGGER, B.G.

1989 A History of Archaeological Thought. Cambridge: Cambridge University Press.

UCKO, P.J. (Ed.)

1995 Theory in Archaeology. A World Perspective. London: Routledge.

WILLEY, G.R.; PHILLIPS, P.

1955 Method and Theory in American Archaeology II: historical-developmental interpretations. American Anthropologist, 57: 723-819.

WYLLIE, A.

1992 The interplay of evidential constraints and political interests: recent archaeological research on gender. American Antiquity, 57: 15-35.

1993 A proliferation of new archaeologies: "beyond objectivism and relativism" N. Yoffee; A. Sherrat (Eds.) Archaeological Theory: Who Sets the Agenda? Cambridge, Cambridge University Press: 14-20. 